\title{
TRANSPARENCIA JUDICIAL Y CENSURA EN MÉXICO
}

\section{Humberto Manuel SARKIS VELÁZQUEZ*}

\section{Planteamiento del problema}

De manera subrepticia, algunos poderes judiciales locales mexicanos han comenzado sigilosamente a ocultar la información pública relativa a las partes en litigio que se publican en los boletines judiciales y listas de acuerdos. Mediante sofismas se pretende justificar la censura previa de los datos públicos, atentando contra la naturaleza jurídica, la deontología y la teleología del boletín judicial.

Es un hecho evidente que la publicación de las listas de acuerdos constituye una obligación fundamental en la impartición de justicia, una formalidad esencial del procedimiento que — de no cumplirse- puede dejar en indefensión a cualquiera de las partes y supone, además, información del dominio público indispensable para la democracia de un país, un instrumento de combate a la corrupción y una obligación ineludible del Estado con sus gobernados. Por otra parte, pretender cancelar información pública judicial que pertenece al dominio público implica un acto de censura.

\section{AnteCedentes, ORIGEN DEL BOLETín JUdiCiAL}

Uno de los instrumentos de comunicación entre las partes de un juicio y el tribunal es el llamado boletín judicial, que no sólo se trata de un interlocutor entre los litigantes y los terceros interesados, sino también un instrumento

\footnotetext{
* Licenciado en derecho por la Facultad de Derecho de la Universidad Nacional Autónoma de México,manuel@sarkis.mx.

Fecha de recepción: 28 de mayo de 2016.

Fecha de dictamen: 14 de septiembre de 2016.
} 
que permite a la sociedad vigilar el comportamiento de los jueces en la impartición de justicia. Por tanto, la información contenida en él es de orden público y posee un interés social fundamental para prevenir la corrupción, generar un comportamiento ético entre las partes, los impartidores de justicia y la sociedad. El 31 de diciembre de 1928 se publicó la Ley Orgánica de los Tribunales del Fuero Común del Distrito Federal y Territorios Federales, reglamentaria de la fracción IV, base IV, del artículo 73 de la Constitución federal, la cual fue modificada y discutida en el periodo ordinario, ${ }^{1}$ estableciendo en el título octavo, "De las publicaciones judiciales", capítulo I, el artículo 207, que se publicará en un diario denominado "Boletín Judicial"

- para dar a conocer los acuerdos, edictos, avisos judiciales, y deberá circular a las nueve de la mañana, y en su parte conducente dice: "en el último número de cada mes, se publicará en el expresado boletín una lista completa de los negocios que se tramiten en los juzgados menores y de primera instancia... Las listas expresarán los nombres de los interesados y números de los expedientes".

La intención de publicar los nombres de los interesados no sólo es una cuestión procesal y de comunicación entre las partes, sino que también tiene la intención de someter la labor del juzgador al escrutinio público. Tomemos como ejemplo — en la actualidad — a las leyes orgánicas de muchos estados de la República, similares a la Ley Orgánica del Tribunal Superior de Justicia de la Ciudad de México, ésta en el capítulo II, "De la Dirección General de los Anales de Jurisprudencia y Boletín Judicial”, artículo 111, fracción II, en el cual indica que las notificaciones en juicio deberán hacerse por boletín judicial.

Podemos percatarnos que uno de los muchos fines del boletín judicial es garantizar el principio de publicidad de los juicios; esto es, poner las listas de acuerdos a disposición de los ciudadanos y no sólo de un gremio, como el de los abogados, sino de toda la sociedad, sujetando el actuar de los juzgadores al escrutinio público. La propia Suprema Corte de Justicia ha resuelto que el Boletín Judicial deberá expresar el número de expediente, la naturaleza del juicio, el nombre y apellido de los interesados, entre otros, ya que de faltar alguno de estos requisitos, dejaría de cumplirse con la finalidad de dicho medio de difusión, que es dar publicidad a las actuaciones; en este sentido, "la ausencia de los datos mencionados se traduce en la inutilidad de dicho órgano informativo..." (Tesis III. 2o.C. 53 C.).

1 XIII Legislatura, t. I, núm. 38, México, 27 de diciembre de 1953. 


\section{ACCESO A LA INFORMACIÓN Y PROTECCIÓN DE DATOS PERSONALES}

Cabe señalar que "el derecho a la información tiene su origen en la libertad de expresión de pensamiento o ideas" (Burgoa, 1972: 355). Sin embargo, ha existido durante toda la historia de la humanidad y es posible encontrar ejemplos desde la Edad Antigua hasta la Contemporánea. En este sentido, el doctor Ignacio Burgoa afirma que "nunca tuvo consagración jurídica sino hasta el advenimiento de la Revolución francesa, pero siempre se ha registrado en el decurso de la humanidad" (1972: 355). Existe una bibliográfica pletórica de los antecedentes históricos de estos derechos que por falta de espacio resulta materialmente imposible mencionar, por lo que sólo nos limitaremos a expresar que el derecho a la información es considerado como una garantía individual, una garantía social y un derecho humano.

Jorge Carpizo, citando a Luis Escobar de la Serna, Sergio López Ayllón y Ernesto Villanueva, expresa que el derecho a la información incluye tres facultades: $a$ ) recibir información objetiva y oportuna; $b$ ) esta información debe ser completa, o sea, el derecho de enterarse de todas las noticias, y c) debe tener un carácter universal, es decir, que la información sea para todas las personas sin exclusión alguna (Valadés y Gutiérrez, 2000: 72). De los anteriores puntos de vista resulta evidente que sería absurdo considerar que el derecho a la información sólo suponga poder buscar, recibir u obtener información, opiniones o ideas si éstas no se pueden difundir, pues la promoción de la información forma parte de la propia libertad de expresión.

El ministro Román Palacios señala que "el solo derecho a ser informado podría decirse que carece de sentido, porque no tiene importancia constituirse en un receptor de datos si éstos no van a ser utilizados para nada; el derecho a ser informado es para el efecto de hacer algo. Un banco de datos no sirve sino se utiliza..." (Valadés y Gutiérrez, 2000: 46). Éste es un punto medular, ya que uno de los argumentos en contra del acceso a la información pública judicial, y específicamente al nombre de las partes litigantes, es el relativo a que la información pública judicial sólo debe ser utilizada por las partes en litigio y que difundirla por un tercero atenta contra la privacidad de los involucrados, lo que desde nuestro punto de vista se contrapone con uno de los elementos esenciales del derecho a la información, que es precisamente la facultad de difundirla. Para la ley, el principio de máxima publicidad consiste en que los entes públicos expongan la información que poseen al escrutinio público, y en caso de duda razonable respecto a la forma de interpretar y aplicar la norma, se optará por la publicidad de la información. 
Uno de los muchos objetivos de publicar en el Boletín Judicial los nombres de las partes, el tipo de juicio, el juzgado en que se tramita y el número de expediente es precisamente hacer identificable el proceso. Lo anterior es con el fin, entre muchos, de que: 1) no se atente contra la garantía de seguridad jurídica de las partes involucradas; 2) que las partes se enteren de la actividad del procedimiento, y 3) que surtan efectos los términos judiciales; pero también es fundamental para que los terceros que no fueron llamados a juicios o quienes se consideren afectados en sus intereses puedan enterarse e intervenir en el procedimiento. En especial, ha sido una constante que algunos juzgados simulen emplazamientos y notificaciones, dejando en - total estado de indefensión a la parte que nunca se enteró del procedimien- to en su contra, y del que llega a tener conocimiento hasta que pierden su patrimonio o su libertad, como ha sucedido en casos de extinción de dominio y juicios mercantiles, entre otros.

Dar acceso a los ciudadanos de manera gratuita, absoluta, abierta, libre y sin restricciones a los acuerdos de los tribunales superiores de justicia a través del Boletín Judicial, impreso o por internet, es una obligación de dichos tribunales, que tiene trascendencia más allá de las partes en litigio, pues hay un interés de la sociedad en conocer cómo y a quién se juzga, siendo importante para el gobernado también accesar a la información para reducir riesgos en los actos jurídicos que realiza; incluso, en el libro Derecho de información en el Poder Judicial, cuyos autores son José Antonio Caballero Juárez, Vanessa Díaz y Ernesto Villanueva, se confirma nuestro criterio, al manifestar que

El interés social fundamental para conocer lo que sucede en el interior de un Poder Judicial radica de manera relevante en la posibilidad de que los ciudadanos conozcan la forma en la que se imparte justicia en la sociedad. De esta manera... también puede ser útil para alertar a la sociedad sobre alguna cuestión que pudiera causar daño a sus miembros... Un caso interesante que ilustra las dos últimas actividades se encuentra en un portal elaborado en México denominado Buró de Información Legal (BIL). El BIL se encarga de proporcionar a sus usuarios datos sobre la evolución de los procesos, pero también funciona como un órgano encargado de compilar datos sobre el comportamiento judicial de diversos actores sociales... es necesario reconocer que la función jurisdiccional es una actividad pública del Estado. Bajo la anterior premisa, debe reconocerse que todo asunto que se ventila en los tribunales involucra necesariamente una cuestión que interesa a la sociedad desde varias perspectivas... En consecuencia, las interrogantes que surgen en relación con el tratamiento de información sobre los procesos necesariamente deben enfrentar las ventajas que implica la publicación de información 
judicial frente al derecho a la vida privada reclamado por las partes (2006: 30 y 31 ).

Con lo anterior resulta claro que la información pública judicial contenida en los boletines judiciales, que como se afirma es una actividad pública del Estado, no sólo tiene importancia para las partes en litigio, sino también es útil a la sociedad.

Eduardo Novoa Monreal refiere que algunos autores consideran a la intimidad como "aquello que se vive detrás de la puerta cerrada y que se explica por el pudor de su intimidad que tiene todo hombre" (Novoa, 1979: 35). A su vez, "Lindon afirma que es la trastienda que todo hombre se reserva para sí, mientras que Lyon Caen lo llama el jardín secreto que cada uno quiere proteger contra la indiscreción” (Novoa, 1979: 35). Para otros, pertenece al patrimonio moral de las personas y constituye la prolongación de su personalidad. Sin embargo, consideramos que no existe ningún choque entre el derecho a la vida privada, el derecho a la intimidad y la publicación de los nombres de las partes en los boletines judiciales.

Un caso que Novoa Monreal nos plantea fue protagonizado por el Tribunal Correccional de París, que desestimó la reclamación de una joven que en el verano de 1970 almorzaba en la playa de Saint Tropez con los senos descubiertos y fue fotografiada en tal situación (Novoa, 1979: 69). La fotografía se publicó posteriormente en el periódico L'Express. El Tribunal determinó que no podía invocarse atentado contra la intimidad de la vida privada, pues se hallaba en la playa, en un lugar público (JCP, 1971, II, 16875). Algo similar podemos decir que sucede con la publicación de los nombres de las partes en los boletines judiciales, pero con la complejidad, amplitud y subjetividad de la definición de dato personal, lo que ha generado el argumento relativo a que publicar los nombres de las partes de un juicio atenta contra su derecho a la privacidad e intimidad.

En su libro Derecho a la vida privada y libertad de información, Eduardo Novoa demuestra cuál de estos derechos debe prevalecer cuando hay contraposición entre ellos. Palabras más, palabras menos, él afirma que esto tiene una explicación histórica: mientras que la interpersonal era la única forma de comunicación humana, el de opinar era el único derecho a la comunicación. Después se inventó la imprenta, y la libertad de expresión fue añadida. La libertad de pensamiento explica la libertad de opinión y de expresión, y éstas — a su vez - fundamentan la libertad del derecho a la información. La libertad de información es un verdadero derecho social, porque interesa y compromete a toda la sociedad y no sólo al individuo. La propia Suprema Corte lo ha considerado en primera instancia como una garantía social y, posteriormente, también como una garantía individual. 
En cambio, los derechos de la personalidad del hombre, como lo es el derecho a la privacidad, miran solamente al ser humano en lo individual, lo que presupone que si en el derecho a la información hay un interés general comprometido que mira por el bien común, podemos decir entonces que el bien común está prominentemente sobre el bien singular de la persona.

Respecto a la publicación de acuerdos sin omitir los nombres y apellidos de las partes en el caso de las personas físicas y el nombre de las personas morales y hasta de sentencias, es necesaria en los países democráticos. Por ello, la cultura de la transparencia y el acceso a la información deben fomentarse y no restringirlas, limitarlas o realizar actos de censura. Esto - asegura la integración y existencia de una opinión pública libre, condición indispensable para la participación ciudadana en la vida pública y política de toda sociedad democrática, pero además permite a la sociedad vigilar y evaluar el comportamiento de la autoridad, ahora que tanto se habla del "gobierno abierto", del que el doctor Guillermo Cejudo refiere: "ofrece una oportunidad muy importante para completar la apuesta de un gobierno democrático: al abrir las puertas a la participación, al fomentar la integración de la voz ciudadana en la toma de decisiones y al facilitar el escrutinio público" (Luna y Bojórquez, 2015: 100). En esta línea, el Consejo de la Judicatura dictó el acuerdo general 68/2004 del Pleno del Consejo de la Judicatura Federal, mediante el que se implementa la publicación en internet de las sentencias ejecutorias y resoluciones públicas relevantes generadas por los tribunales de circuito y juzgados de distrito, a fin de incentivar el interés de la población en el conocimiento de las resoluciones jurisdiccionales y para fomentar una cultura de transparencia y acceso a la información.

Por su parte, la Suprema Corte de Justicia de la Nación emitió el siguiente criterio:

Transparencia y aCCESo a la información pública gubernamental. Resulta ineficaz la oposición a la inclusión de los datos personales en la publicidad de los asuntos del conocimiento del poder judicial de la federación cuando aquellos no revistan la característica de reservados de conformidad con el artículo 13, fracción IV, de la ley federal relativa (Tesis IV.2o.A.139 A).

\section{Censura}

El Poder Judicial de la Ciudad de México, en materia civil, es un ejemplo de transparencia, dado que si bien no llega al estándar de la Suprema Corte de Justicia o al que Michoacán tenía antes de autocensurarse, publica las listas de acuerdos sin omisión alguna, tanto en papel como en su página 
web y en disco compacto, aunque no agrega un resumen del acuerdo ni cuenta con versiones públicas de todas las sentencias. Es un buen comienzo, pues la ciudadanía puede dar seguimiento a un juicio de manera ágil y gratuita sin importar si se trata de un político "de renombre", un presunto "narcotraficante" o un empresario.

No obstante, resulta lamentable la leyenda que el tribunal pone en sus boletines judiciales y disco compacto, expresando que tienen protección de derechos de autor y que su reproducción parcial o total está prohibida. Ahora bien, al registrar el Boletín Judicial en el Instituto Federal de Derechos de Autor (número de registro 03-2010-060313124100-01) se cometió un dislate al designar a un particular como autor y el Tribunal Superior de Justicia de la Ciudad de México como titular de la obra, lo que llevó al Consejo de la Judicatura de dicho tribunal a declarar a tal registro como información reservada para evitar un escándalo mayúsculo, siendo obvio que la información de dominio público no puede tener derechos de autor ni limitarse su uso.

De esta forma, no existe transparencia en el Tribunal Superior de Justicia de la Ciudad de México en materia penal, ya que las listas de los acuerdos de los procesos penales no se publican en el Boletín Judicial, lo que ha provocado escándalos de corrupción y juicios paralelos por parte de los medios de comunicación y en las redes sociales. Actualmente, algunos tribunales de la República mexicana se han resistido a facilitar el acceso a la información pública generada por esos organismos; especialmente, al boletín judicial, tal resistencia se ha evidenciado mediante la emisión de boletines judiciales en donde no se incluyen los nombres ni los datos del procedimiento, limitándose a un simple listado de números de expediente, lo que además atenta contra una de las facultades que tiene el gobernado respecto del derecho al acceso a la información y que consiste en tener acceso a la información completa. Actuar que implica una censura previa, además, atenta contra la naturaleza jurídica y teleológica del Boletín Judicial y se presta a la tramitación de juicios a espaldas de algún demandado, simulando domicilios o emplazamientos y notificaciones falsas, inclusive contra partes simuladas, y lo único que genera es una oportunidad para convertir a los tribunales en agencias de venganzas y simulaciones, lejos de la vigilancia de la sociedad.

En un principio, se pensaba que esconder la información - y, en especial, el nombre de las partes - era únicamente una actitud de resistencia al cambio o temor de que la sociedad se percatara del retraso en la impartición de justicia. Sin embargo, la realidad va más allá de las meras cuestiones administrativas, y lo cierto es que reservar los nombres de las partes en el 
Boletín Judicial y la información de los juicios también tiene implicaciones de encubrimiento, corrupción y complicidad, no sólo al ocultar la información de los servidores o ex servidores públicos que litigan en los tribunales, sino también la de los presuntos delincuentes que son buscados internacionalmente y que litigan en los tribunales menos transparentes, además de ser un medio idóneo para el lavado de dinero. Encontramos destacados ejemplos de censura previa o autocensura en estados como Colima, Puebla, Michoacán, Oaxaca, Hidalgo y Nayarit; en el caso de Veracruz no hay censura previa, pero se comienzan a cancelar datos en los boletines judiciales en línea, lo que se hizo patente mediante la resolución al recurso de revisión

- núm. VAI-REV-DP/01/2015, interpuesto ante el Instituto Veracruzano de

- Acceso a la Información Pública y Protección de Datos Personales. Es muy importante este tópico de cancelación de datos de información pública, que por falta de espacio no podemos profundizar, pero consideramos que las autoridades encargadas de la transparencia, acceso a la información pública y protección de datos han olvidado un concepto muy importante como es el de dominio público. La información pública, desde nuestro punto de vista, lleva intrínseca la característica de pertenecer al dominio público y, por lo tanto, no debe ni puede cancelarse por parte de su generador, mucho menos por quienes lo difunden, tratan o son el medio para que la sociedad acceda a ella.

\section{Tamaulipas}

Silenciosa y misteriosamente, el Tribunal de Tamaulipas dejó de publicar el nombre de las partes y el tipo de juicio en el boletín judicial y sólo hacía mención de los números de los expedientes. Sin embargo, tras seleccionar al azar uno de los personajes enumerados en la lista del tesoro de los Estados Unidos de América y que son señalados como presuntos financiadores del narcotráfico, proliferación de armas de destrucción masiva o terrorismo, entre otros (Office of Foreign Assets Control, OFAC); en el caso de Alfredo $\mathrm{R} \mathrm{B}^{2}$ se comprobó que aparecía litigando en el tribunal de Tamaulipas, y antes de ocultar la información, podíamos consultar y conocer, entre otros, un procedimiento tramitado por esta persona en el boletín judicial de dicho estado. ${ }^{3}$ En mayo de 2016, nuevamente el tribunal de Tamaulipas volvió a hacer públicos los datos en el boletín judicial ante los múltiples señalamientos de esa censura previa.

2 También uno de los más buscados por la Drug Eforcement Administration, disponible en: http://www.dea.gov/fugitives.shtml.

3 Expediente 1529/2008, publicado el 14 de diciembre de 2011. 
Por el contrario, y como muestra de transparencia, la Suprema Corte de Justicia de la Nación sí hace públicos todos los procedimientos y amparos tramitados ante los juzgados y tribunales del máximo tribunal, lo que permite a los ciudadanos conocer, incluso, la versión pública de los fallos emitidos, para que, de igual forma, supervisen la actuación de los impartidores de justicia, generando así transparencia, confianza y democracia.

\section{Michoacán}

El Boletín Judicial de Michoacán era uno de los más transparentes de México, y en él no sólo se publicaban los nombres de las partes y el tipo de juicio, sino que también se hacía un extracto del acuerdo o la sentencia. Sin embargo, algo extraño sucedió cuando el tribunal de Michoacán dejó de publicar los mencionados nombres de las partes y se limitó, como en Tamaulipas, Puebla, Colima, Hidalgo, Oaxaca, Tlaxcala y Nayarit, a señalar en el boletín de su página de internet, únicamente los números de expedientes. Nuevamente se pone de manifiesto que en el tribunal litigan políticos y empresarios que tienen contratos con los gobiernos locales, personajes que son buscados internacionalmente o señalados en listas internacionales como presuntos financiadores del narcotráfico o del terrorismo, y se agrega, más adelante, el resultado de la investigación y análisis de la lista de la OFAC con relación a los tribunales donde litigan las personas mencionadas en esas listas.

\section{Puebla, Hidalgo, Nayarit, Colima, Oaxaca y Tlaxcala}

Estos estados son los menos transparentes del país con relación a su publicación de listas de acuerdos y boletín judicial, ya que Puebla, Hidalgo, Nayarit, Colima y Oaxaca sólo publican el número de expediente de cada juicio, sin ningún otro dato. En el caso de Puebla han ocurrido hechos indignantes que han llegado a la justicia federal — como los del "gober precioso", Kamel Nacif y Jean Succar-; el tribunal de este estado también oculta los nombres de los litigantes, por lo que la ciudadanía no puede supervisar la forma en que los juzgadores realizan su labor. En efecto, casos como el de Lydia Cacho - en el que una ciudadana fue víctima del abuso del poder - y muchos otros probablemente no hubieran presentado desenlaces tan indignantes si hubiera existido transparencia y acceso a la información en el tribunal de Puebla. En cuanto al caso de Tlaxcala, ni siquiera cuenta con un boletín judicial, y su página web es muy austera. 
Evidentemente, los casos de políticos que litigan en los tribunales, que simulan juicios, que demandan por millones, que tramitan juicios sucesorios en los que resultan ser los herederos o que reciben favores para obtener sentencias en su beneficio son muchos. Sin embargo, la impunidad, corrupción y tráfico de influencias son mayúsculos al no existir transparencia ni posibilidad de acceder a la información; además, el lavado de dinero se encubre mediante los juicios simulados.

\section{SOFISMA}

- Algunos académicos de los países menos transparentes de América y la corriente europea han venido a convencer y persuadir a los tribunales de México para implementar el derecho al olvido y la protección de los datos personales, fuera de su dimensión, alcance real y constitucional, con el sofisma de que la información judicial únicamente debe ser accesible a las partes del juicio. Con tal pretexto, algunos de los tribunales han comenzado a ocultar la información mencionada y a cancelar datos públicos de las listas de acuerdos, a petición de quien se dice afectado o de motu proprio que es lo más grave, y provoca, desde nuestro punto de vista, lo que denomina la doctora Issa Luna Pla como "la pobreza informacional". Pero ¿qué ocurre en Reino Unido, Canadá, Estados Unidos o Suecia?, ¿por qué el índice de impunidad es tan bajo en estos países?, ¿por qué pueden llevar a juicio a un presidente como Clinton o Nixon, clausurar cuatro cárceles por falta de reos, etcétera? La respuesta es evidente: uno de los elementos clave en esas naciones es el libre acceso a la información y la transparencia en los procedimientos legales. Esto, además, evita juicios paralelos, toda vez que la prensa puede conocer los casos que se siguen en las cortes y tribunales de dichos países.

En todos los países del primer mundo, el acceso, uso, consulta y difusión de la información pública judicial está garantizada por el Estado, y especialmente por los países democráticos, sólo basta ver el ejemplo de los Estados Unidos, "lo que la Ley federal ha establecido es que, a pesar de los sellos de privacía que los jueces pueden ordenar, la regla es que los procedimientos judiciales son públicos, y que los acuerdos de los juzgados también son considerados registros públicos" (Concha et al., 2005: 195). Desde nuestro punto de vista, existe lo que denomina Issa Luna como "el empoderamiento de los gobiernos a los ciudadanos", afirmando que "el derecho de acceso a la información posee una cualidad de empoderamiento de los más débiles para gozar de iguales oportunidades que otras personas" (Luna, 2010: 42), hecho contrario a lo que sucede en algunos tribunales mexicanos, en donde no existe ningún medio para acceder a la informa- 
ción pública judicial. El acceso a la información, según refiere Luna, "es un derecho fundamental porque reivindica el acceso a la información del más débil frente al poderoso que detenta la información” (Luna, 2010: 42).

\section{Lista OFAC-MÉXICO}

El presente análisis tiene por objeto conocer con brevedad algunos tópicos que pueden ser útiles para las autoridades mexicanas y la propia sociedad. Los datos de este estudio fueron obtenidos de fuentes de acceso público. Sin embargo, los datos no se encuentran procesados ni analizados en esas fuentes, específicamente la llamada Specially Designated Nationals List (SDN), consultable en la página web del Departamento del Tesoro de los Estados Unidos, ${ }^{4}$ de la cual logramos obtener y generar la siguiente información estadística mediante la información generada en el Buró de Investigaciones Legales (www.bil.com.mx), empresa facilitadora de acceso a la información pública y que permite hacer búsquedas específicas como la referida.

Así, el 16\% de las personas y empresas enlistadas por la Office of Foreign Assets Control (OFAC) son de origen mexicano. El 17\% de esas personas o empresas mexicanas cuentan con el Registro Federal de Causantes y el $5 \%$ con concesiones y contratos con el gobierno federal, lo que implican 75 contratos y concesiones. Los principales concesionarios son la Comisión Nacional del Agua, Pemex y la Secretaría de Comunicaciones y Transportes. Por otra parte, 96 personas físicas y/o morales enlistadas por la OFAC litigan en tribunales mexicanos. Los territorios de la República mexicana en los que se reporta mayor actividad judicial de personas enlistadas por la OFAC (promoción de demandas como actores, demandados, amparos, juicios de nulidad, procesos penales, etcétera) son Baja California Norte, Durango, Hidalgo, Michoacán, Oaxaca, Zacatecas, Sinaloa y Tabasco. En el caso de los estados como Puebla, Hidalgo, Tlaxcala, Oaxaca, Nayarit o Colima - que no publican los nombres de las partes - sólo se pudo obtener información de las personas que promovieron amparo contra las autoridades judiciales locales, por lo que su porcentaje de litigios podría superar por mucho a los estados que hacen públicas las listas de acuerdos sin censura.

\section{Conclusiones}

El derecho de acceso a la información y a la libertad de expresión no sólo es una garantía individual y un derecho humano, sino también una garantía so-

4 Disponible en: https://www.treasury.gov/ofac/downloads/sdnlist.pdf. 
cial, y está por encima del interés particular. La protección de los datos personales no puede suponer una censura previa o retrospectiva de la información pública judicial. El acceso a la información pública es una obligación del Estado, y respecto a la lista de acuerdos y el Boletín Judicial, también es una obligación de transparencia de oficio, ya que la publicación de listas de acuerdos satisface un interés público en el acceso a la información. Poner en los boletines judiciales sólo los números de los expedientes y ocultar las partes en litigio, además de que se traduce en la inutilidad de ese medio, es un acto de censura previa que restringe los derechos fundamentales y la libertad de expresión, que son, según nuestro máximo tribunal, indispensa- bles para la formación de la opinión pública, necesarias para el funciona- miento de una democracia representativa (Tesis P./J. 24/2007).

El mal llamado "derecho al olvido", relativo a la información pública judicial, es una forma de censura moderna que utiliza nuevos conceptos jurídicos para cancelar o desaparecerla, ya que no debe ni puede aplicarse a la información pública por pertenecer ésta al dominio público. Por el contrario, el acceso a la información pública judicial tiene que ser garantizado por el Estado de forma veraz, completa, y su limitación debe aplicarse sólo en casos de excepción. De otra forma, las autoridades únicamente estarían buscando una justificación para ocultar, silenciar y borrar la información pública de hechos efectivamente acaecidos, que también implican un acervo histórico importante para la nación.

El acceso a la información pública judicial y la libertad de expresión que implica su difusión son esenciales en un país democrático, porque permiten formar la opinión pública, la supervisión de las autoridades, la rendición de cuentas, combatir la corrupción, fomentar la seguridad jurídica de los integrantes de la sociedad; facilitan tomar decisiones; previenen vulnerabilidades entre los miembros integrantes de la sociedad; posibilitan cumplir las leyes fiscales, de lavado de dinero y de extinción de dominio; facilitan la labor de los abogados, entre muchas otras. Lo anterior presupone que una sociedad a la que se restringe el ejercicio de esa libertad de acceso a la información pública judicial no es plenamente libre, o sea, es una democracia falsa, y - como diría nuestro respetado doctor Guillermo Floris Margadant - "un regreso a la época de las pelucas". El derecho a cancelar datos públicos sólo generará censura, impunidad, encubrimiento y complicidad.

El interés público se encuentra por encima del "derecho al olvido" o protección de los datos personales y, así, Ernesto Villanueva refiere que "de esta manera, puede resultar importante conocer la forma en que las empresas se comportan y si las mismas suelen tener problemas en el cumplimien- 
to de sus obligaciones. También puede ser útil para alertar a la sociedad sobre alguna cuestión que pudiera causar daños a sus miembros" (Caballero et al., 2006: 14).

Una de las principales ventajas que derivan de poner la información oficial en el dominio público es la transparencia de la gestión del gobierno y la promoción de ideales democráticos: la igualdad, la democracia y la apertura. Cuanta más información del gobierno y sobre el gobierno se pone a disposición del público, menos probabilidades hay de que el gobierno oculte los actos ilícitos, la corrupción y la mala administración (Uhlir, 2004: V).

Obligar a ocultar, cancelar o censurar previamente información pública del dominio público, hacerla inaccesible con el pretexto del "derecho al olvido" o "protección de datos personales" en un país como México — que tiene el más bajo nivel de desempeño en materia de transparencia-, con la corrupción desmedida, con el asesinato de miles de periodistas, ciudadanos y jóvenes, con la desaparición de mujeres, con los escándalos de pederastia, con casos como Ayotzinapa y escándalos como el de "las casas blancas", permitirá encubrir a políticos, empresarios involucrados en presuntos actos de corrupción y conflictos de interés.

La información de las listas de acuerdos y boletines judiciales forma parte de los registros públicos, es de interés público y, aun con el transcurso del tiempo, tiene un interés histórico respecto al comportamiento de una persona o un juzgador y al control de la actividad de quienes impusieron la sanción o emitieron las sentencias, y con ello, saber si quien emitió la sentencia o impuso una sanción fue injusto o corrupto. Por lo que "el acceso a la información judicial tiene una doble vertiente, como mecanismo de combate a la corrupción y rendición de cuentas y como herramienta para coadyuvar al acceso a la justicia en términos de equidad e imparcialidad" (Caballero et al., 2006: 14). Los poderes judiciales locales deben utilizar como modelo a la lista de acuerdos de la Suprema Corte de Justicia de la Nación, con el fin de que todos cumplan con un estándar en los campos que integran la lista de acuerdos; esto es, juzgado, fecha de publicación, fecha del acuerdo, tipo de procedimiento, actor, demandado y resumen del acuerdo. "En los Estados autoritarios no es posible ejercer el derecho a la información, pues el Estado brinda la información de forma parcial y sesgada; en cambio, en las sociedades democráticas la información se debe proporcionar de manera oportuna, imparcial y objetiva" (Aparicio, 2016: 106). 
Esta revista forma parte del acervo de la Biblioteca Jurídica Virtual del Instituto de Investigaciones Jurídicas de la UNAM

\section{Fuentes DE INFORMACIÓN}

Aparicio, Arturo, 2016, "El derecho de acceso a la información en el marco jurídico interamericano, relatoría especial para la libertad de expresión de la Comisión Interamericana de Derechos Humanos", Revista Estudios en Derecho a la Información, México, núm. 1, enero-junio.

Burgoa, Ignacio, 1976, Las garantías individuales, México, Porrúa.

Caballero, José Antonio et al., 2006, Derecho de acceso a la información en el Poder Judicial, México, Cámara de Diputados, LIX Legislatura: Libertad de Información-Fundación Konrad Adenauer Stiftung-Miguel Ángel Porrúa.

Concha, Hugo A. et al. (coords.), 2005, Transparentar al Estado: la experiencia mexicana de acceso a la información, México, UNAM, Instituto de Investigaciones Jurídicas.

Luna Pla, Issa, 2010, Transparencia, acceso a la información tributaria y el secreto fiscal, México, UNAM, Instituto de Investigaciones Jurídicas.

y Bojórquez, José A. (coords.), 2015, Gobierno abierto, el valor social de la información pública, México, UNAM, Instituto de Investigaciones Jurídicas.

NovoA, Eduardo, 1979, Derecho a la vida privada y libertad de información: un conflicto de derechos, México, Siglo XXI.

Tesis III.2o.C.53 C, Semanario Judicial de la Federación y su Gaceta, Novena Época, t. XV, febrero de 2003.

Tesis IV.2o.A.139 A, Semanario Judicial de la Federación y su Gaceta, Novena Época, t. XXI, mayo de 2005.

Tesis P./J. 24/2007, Semanario Judicial de la Federación y su Gaceta, Novena Época, t. XXV, mayo de 2007.

Uhlir, Paul F., 2004, Orientaciones sobre politicas para la elaboración y promoción de información oficial de dominio público, París, UNESCO.

Valadés, Diego y Gutiérrez, Rodrigo (coords.), 2001, Derechos humanos. Memoria del IV Congreso de Derecho Constitucional III, México, UNAM, Instituto de Investigaciones Jurídicas.

Villanueva, Ernesto, 2003, Derecho de acceso a la información pública en Latinoamérica, México, UNAM, Instituto de Investigaciones Jurídicas. 